\title{
Immediate effect of delayed auditory feedback on stuttering-like disfluencies
}

Paula Bianca Meireles de Moura Buzzeti ${ }^{(1)}$

Cristiane Moço Canhetti de Oliveira ${ }^{(1)}$

(1) Faculdade de Filosofia e Ciências, Universidade Estadual Paulista Júlio de Mesquita Filho - UNESP, Marilia, SP, Brasil. Study carried out at Laboratório de Estudos da Fluência - LAEF, Departamento de Fonoaudiologia da Faculdade de Filosofia e Ciências, Universidade Estadual Paulista "Júlio de Mesquita Filho" - UNESP Marília, São Paulo, Brasil.

Research support source: Coordenação de Aperfeiçoamento de Pessoal de Nível Superior - CAPES.

Conflict of interests: Nonexistent

\section{(c) (i)}

Received on: December 11, 2017 Accepted on: April 3, 2018

\section{Mailing address:}

Cristiane Moço Canhetti de Oliveira Av. Hygino Muzzi Filho, 737, Vila

Universitária

CEP: 17525-000 - Marília, São Paulo,

Brasil

E-mail: cmcoliveira@marilia.unesp.com.br

\section{ABSTRACT}

Objective: to describe the immediate effects of delayed auditory feedback on stuttering-like disfluencies in people who stutter.

Methods: a cross-sectional and experimental study. The effect of delayed auditory feedback was analyzed in thirty individuals, from eight to 46 years old, diagnosed with persistent developmental stuttering. Participants should present at least $3 \%$ of stuttering-like disfluencies and mild stuttering according to the Stuttering Severity Instrument. The following procedures were used: audiological evaluation, fluency evaluation in two listening situations - with Non-altered and delayed auditory feedback and the Stuttering Severity Instrument. The Fono Tools software was used to cause the delay effect. Data analysis was performed using pertinent statistical tests.

Results: there was no decrease in most stuttering-like disfluencies. There was a statistically significant reduction in word repetition and flow of syllables per minute.

Conclusion: the delay in auditory feedback caused, as an immediate effect, the reduction of word repetition and speech rate, in syllables per minute.

Keywords: Speech, Language and Hearing Sciences; Speech Disorders; Stuttering; Feedback; Hearing 


\section{INTRODUCTION}

Stuttering is a speech disorder notoriously characterized by syllable repetitions, prolongations, and blocks ${ }^{1}$. These excessive stuttering-like disfluencies during the linguistic formulation of speech $^{2-4}$ impair smoothness $^{5}$ and the speech rate $^{6}$ during speech. Therefore, one of the general objectives of speechlanguage therapy in stuttering is to reduce disfluencies, and consequently promote fluency.

Although the etiology of stuttering is still unknown ${ }^{7,8}$, some of the more prominent and contemporary theoretical views suggest that the disorder may result from deficits in specific sensory-motor integration processes, which are fundamental for both initial motor speech learning and motor control of mature speech ${ }^{9}$. Different patterns of brain activity in the motor and left auditory regions, with increase of activation in the right hemisphere, were found in persons who stutter in comparison to fluents ${ }^{10}$. Electrophysiological evidences have reinforced the hypothesis that stuttering is associated with a deficit in the modulation of the cortical auditory system during speech planning and that this may contribute to inefficient monitoring of auditory feedback and, consequently, result in speech disfluencies ${ }^{11}$.

Auditory feedback refers to the speech sounds received by the speaker's own auditory system during oral production and it is an important component of the mechanisms of speech movements control ${ }^{9}$. When a sudden irregularity occurs in a specific acoustic parameter of auditory feedback, fluent speakers are able to correct the mistake in their oral production instantaneously ${ }^{9}$, while persons who stutter have shown weaker than normal compensation when experiencing these occurrences ${ }^{9,12}$. These findings indicate that persons who stutter are not able to compare audibly desired speech movements to real movements as well as fluent speakers do ${ }^{13,14}$

With the advent of technology, there was an increase in the investigation of resources that could aid speechlanguage intervention in stuttering, for example, the use of altered auditory feedback ${ }^{12-15}$. Among these investigations, many studies have pointed to the benefits of delayed auditory feedback during speech situations for persons who stutter ${ }^{16-19}$ and have provided evidences that auditory feedback from flow of continuous speech is used to maintain fluency in the course of oral emission ${ }^{20}$. Some studies have shown that stutteringlike disfluencies can be immediately reduced by $60 \%$ to $100 \%$ when persons who stutter perceive altered auditory feedback ${ }^{13,14}$.

The delayed auditory feedback resulted as an immediate effect improvement in the fluency of persons who stutter without affecting the speech naturalness ${ }^{19}$. A mean reduction of $35 \%$ in the frequency of stuttering with the use of DAF by Pocket Speech Lab (Casa Futura Technologies ${ }^{\circledR}$ ) has been reported ${ }^{20}$.

The effects of speech therapy were compared in one group without and other with using the SpeechEasy device ${ }^{21}$. The results showed that both groups decreased the degree of stuttering and the amount of stuttering-like disfluencies in the post-therapy evaluation. However, the group that used SpeechEasy presented a greater tendency to reduce disfluencies and greater gain in articulatory rate and information production rate ${ }^{21}$. A recent randomized clinical trial investigated the use of SpeechEasy and concluded that this is a viable device for the treatment of stuttering ${ }^{19}$.

Other studies have shown as immediate effects of DAF a significant reduction in the frequency of stuttering, being blocks reduction significantly greater than prolongations and repetitions. There was no significant effect on the speech rate ${ }^{18}$.

In view of the abovementioned information, the benefits that the delayed auditory feedback cause in the fluency of persons who stutter are notorious. However, not all individuals show a significant improvement with the use of this resource. Based on the hypothesis that the type of disfluency may influence the effectiveness of delayed auditory feedback as an intervention in the treatment of stuttering, this study aimed to compare the immediate effects of delayed auditory feedback on the different typologies of stuttering-like disfluencies in individuals affected by the disorder.

\section{METHODS}

The study was approved by the Research Ethics Committee of the Universidade Estadual Paulista "Julio de Mesquita Filho" (UNESP), where the study was carried out (№ 911.186/2014). The Informed Consent Form was signed by the responsible for each individual or by the own individual (when over 18 years of age). Participants 12 years old and under 18 signed the Informed Assent Form.

Thirty individuals (both genders) diagnosed with Persistent Developmental Stuttering, aged between 8 and 46 years and 11 months of age, participated in this study. The diagnosis was made in a specialized 
laboratory, linked to the university where the study was carried out.

As an inclusion criterion, individuals should: to be native speakers of Brazilian Portuguese; age between eight to 59 years and 11 months; to have normal hearing thresholds ${ }^{22}$, to present a complaint of stuttering; the onset of the disorder should have occurred during childhood (developmental stuttering); disfluencies without remission (persistent); to present at least 3\% of stuttering-like disfluencies ${ }^{23}$, stuttering rated at least as mild according to the Stuttering Severity Instrument $(\mathrm{SSI}-3)^{24}$ and never having experienced previously delayed auditory feedback.

The procedures of this research were grouped in three stages. In the first one, the collection of identification data was performed, in which the participants (or their legal caregivers, when underage) signed the Informed Consent Term in accordance with the resolution of the Health National Council (Conselho Nacional de Saúde - CNS) 466/2012. After, it was collected the clinical history. The participants, or their caregivers, were questioned orally about age, gender, health history, history of speech and language disorders; complaint and prior history of the complaint, and; familial history. Individuals who presented alterations of oral communication not compatible with the age were excluded; any other oral communication disorder, other than stuttering, and written communication; and/ or other pertinent conditions that could generate errors in the diagnosis. In order to fulfill the inclusion and exclusion criteria, the individuals were submitted to basic audiological assessment and anamnesis procedures and speech fluency evaluation.

The second stage consisted of basic audiological assessment - pure tone audiometry, speech audiometry with speech recognition threshold (SRT) and immitance measurement. Hearing was considered normal when the pure-tone thresholds average in the frequencies of $500 \mathrm{~Hz}, 1000 \mathrm{~Hz}$ and $2000 \mathrm{~Hz}$ was equal to or less than $25 \mathrm{dBHL}$, the result of the SRT was equal to or at most $10 \mathrm{~dB}$ above this mean and the presence of a tympanometric curve of type $A$ in immitance measurement.

In the third stage, the fluency evaluation was performed. For each participant, samples of spontaneous speech were collected through audiovisual recording in two different listening conditions: with non-altered and delayed auditory feedback. The sequence of tasks recordings was the same for all participants.
Firstly, it was performed the collection of spontaneous speech in the non-altered listening condition, in which the participants were instructed to report topics of their daily life. For example, talk about the routine, about topics that were being addressed at school or at work, as well as the report of leisure activities held in their free time. In order to reach the necessary speech sample, the evaluator stimulated with questions in order to assist the participant in the continuation of the speech, when necessary. At the time of the evaluation the participants did not use earphones.

Then, it was carried out the collection of spontaneous speech sample in the listening condition with delayed auditory feedback. The discussed topic was different from the speech collection in the non-altered listening condition, to avoid the effect of adaptation. All the participants were informed about the echo sensation that the earphone would produce. In relation to the children, a test was carried out before the procedure was started in order to that they would experience the sensation and better understand what would happen.

The recordings were performed with the participant sitting in front of the evaluator, in a quiet environment. For the speech sample in listening condition with delay, each participant was instructed to report situations of their daily life with earphones (with microphone) adjusted, and connected to a computer, in which specific software was used. The participant's speech was recorded and processed through the Fono Tools software that performed auditory feedback with delay of $100 \mathrm{~ms}$.

The speech samples were transcribed in a total of 200 fluent syllables for each sample as proposed in the literature ${ }^{25}$ considering fluent and non-fluent syllables. Subsequently, the speech samples were analyzed and the disfluencies typology was characterized, according to the following description ${ }^{26}$ :

- Stuttering-Like disfluencies: word repetition above 3, syllable repetition, sound repetition, block, prolongation, pause, intrusion, and;

- Other disfluencies: interjection, hesitation, revision, incomplete words, phrase repetition, word repetition - up to 2.

For the stuttering diagnosis, the criterion was the presence of at least $3 \%$ of stuttering-like disfluencies and stuttering classified at least as mild in the Stuttering Severity Instrument - SSI- $3^{24}$. These data were reached through the speech sample in the non-altered listening condition, being considered as a control condition. 
To classify the participants' stuttering as mild, moderate, severe or very severe the Stuttering Severity Instrument $\mathrm{SSI}^{-3^{24}}$ was used. This test evaluates the frequency and duration of stuttering-like disfluencies, and the presence of physical concomitants associated with disfluencies.

\section{Statistical analysis}

In this study, comparative analyzes of the speech fluency data of each participant were performed between the non-altered and delayed auditory feedback situations. Some measures were calculated, such as: mean, median, minimum and maximum values, standard deviation and $p$ value.

Non-parametric tests, Wilcoxon, Mann-Whitney and Chi-square tests were used for statistical analysis, since the histograms relative to the analyzed variables did not present a Gaussian distribution ( $p>0.05)$. The correlation between the effect of DAF on word repetition and flow of syllables per minute was performed by means of Spearman Coefficient for variables with non-normal distributions, in order to measure the degree of association between two quantitative variables of interest. In cases in which the variables were normal, ANOVA was used. In all analyzes, the level of significance was $5 \%$. Data analysis was performed using the Statistical Package for Social Sciences program in its version 22.0 (SPSS 22.0 for Windows).

\section{RESULTS}

Table 1 presents the characterization of participants of this study. It is possible to observe a higher prevalence of male participants (76.6\%). The percentage of stuttering-like disfluencies ranged from 3 to $36.5 \%$. The stuttering severity varied from mild to very severe, and the diagnosis of mild stuttering was the most prevalent (46.6\%), followed by moderate $(36.6 \%)$, very severe $(10.0 \%)$ and severe $(6.6 \%)$ respectively.

The descriptive values of duration of disfluencies (blocks, prolongations and pauses) and repetition disfluencies (word, part of word and sound repetitions) in each listening situation (Table 2) showed that, for repetition disfluencies, there was difference significant.

The occurrence of each stuttering-like disfluency under both listening conditions - non-altered and delayed - was compared and presented in Table 3. There was no reduction of most disfluencies under the effect of delayed auditory feedback. The word repetition was the only type of disfluency that showed significant reduction under the effect of delay.

The results regarding the immediate effect of delay in the auditory feedback for each typology of stutteringlike disfluency are presented in Table 4. There was a reduction of word repetition and intrusion maintenance. It is noteworthy that, 25 individuals did not present intrusion in the evaluation of the NAF and of these 24 still did not present in the evaluation of the DAF.

Table 5 presents the descriptive statistics for the speech rate - syllables per minute and words per minute - and percentage of stuttering-like disfluencies in listening conditions with non-altered and delayed auditory feedback. There was a reduction in the flow of syllables per minute under the effect of delay.

A statistical study was performed regarding the existence of a possible correlation between word repetition and flow of syllables per minute using the Spearman Coefficient. It was found that there was no correlation between these variables $\left(r_{s}=-0,080\right.$, $p>0,050$ ). 
Table 1. Characterization of study participants

\begin{tabular}{|c|c|c|c|c|c|c|c|c|}
\hline $\mathrm{N}^{0}$ & Gender & Age & SLD Total & $\%$ SLD & SPM & WPM & $\begin{array}{l}\text { SSI-3 } \\
\text { Score }\end{array}$ & Stuttering severity \\
\hline 1 & $M$ & 33 & 16 & 8.0 & 184.6 & 101.5 & 21 & Mild \\
\hline 2 & $M$ & 22 & 17 & 8.5 & 164.3 & 82.1 & 21 & Mild \\
\hline 3 & M & 36 & 10 & 5.0 & 235.2 & 142.3 & 19 & Mild \\
\hline 4 & $M$ & 10 & 15 & 7.5 & 80.0 & 46.0 & 20 & Moderate \\
\hline 5 & $\mathrm{~F}$ & 8 & 39 & 19.5 & 48.0 & 28.0 & 29 & Severe \\
\hline 6 & M & 8 & 8 & 4.0 & 144.5 & 77.3 & 17 & Mild \\
\hline 7 & $M$ & 12 & 12 & 6.0 & 184.0 & 97.0 & 21 & Moderate \\
\hline 8 & $M$ & 28 & 12 & 6.0 & 235.2 & 130.5 & 27 & Moderate \\
\hline 9 & $M$ & 12 & 10 & 5.0 & 244.8 & 140.8 & 19 & Mild \\
\hline 10 & $M$ & 46 & 22 & 11.0 & 160.0 & 97.6 & 28 & Moderate \\
\hline 11 & M & 20 & 18 & 9.0 & 200.0 & 108.0 & 23 & Mild \\
\hline 12 & $\mathrm{~F}$ & 8 & 10 & 5.0 & 126.0 & 77.0 & 22 & Moderate \\
\hline 13 & M & 9 & 13 & 6.5 & 200.0 & 92.0 & 22 & Moderate \\
\hline 14 & $M$ & 12 & 6 & 3.0 & 89.0 & 55.0 & 14 & Mild \\
\hline 15 & $\mathrm{~F}$ & 13 & 8 & 4.0 & 94.0 & 55.0 & 18 & Mild \\
\hline 16 & $M$ & 13 & 9 & 4.5 & 218.1 & 133.0 & 18 & Mild \\
\hline 17 & $M$ & 9 & 19 & 9.5 & 100.0 & 57.0 & 27 & Moderate \\
\hline 18 & M & 8 & 73 & 36.5 & 50.0 & 31.0 & 39 & Very Severe \\
\hline 19 & $M$ & 13 & 10 & 5.0 & 89.0 & 56.0 & 22 & Moderate \\
\hline 20 & $M$ & 46 & 7 & 3.5 & 187.5 & 94.6 & 15 & Mild \\
\hline 21 & M & 17 & 6 & 3.0 & 292.0 & 157.0 & 20 & Mild \\
\hline 22 & $\mathrm{~F}$ & 9 & 35 & 17.5 & 60.0 & 34.0 & 41 & Very Severe \\
\hline 23 & $\mathrm{~F}$ & 19 & 19 & 9.5 & 137.9 & 82.7 & 32 & Severe \\
\hline 24 & M & 17 & 20 & 10.0 & 169.0 & 96.3 & 27 & Moderate \\
\hline 25 & $\mathrm{~F}$ & 23 & 8 & 4.0 & 218.1 & 133.0 & 19 & Mild \\
\hline 26 & $M$ & 21 & 11 & 5.5 & 193.5 & 118.0 & 19 & Mild \\
\hline 27 & M & 13 & 35 & 17.5 & 81.0 & 46.0 & 37 & Very Severe \\
\hline 28 & $\mathrm{~F}$ & 8 & 35 & 17.5 & 30.0 & 20.0 & 26 & Moderate \\
\hline 29 & M & 26 & 11 & 5.5 & 196.7 & 115.0 & 19 & Mild \\
\hline 30 & $M$ & 17 & 20 & 10.0 & 127.6 & 77.2 & 26 & Moderate \\
\hline Mean & - & 17.8 & 17.8 & 8.9 & 151.3 & 86.0 & 23.6 & - \\
\hline SD & - & 10.7 & 13.9 & 6.9 & 67.7 & 37.7 & 6.7 & - \\
\hline
\end{tabular}

Legend: $\mathbf{N}=$ Number; $\mathbf{M}=$ Male; $\mathbf{F}=$ Female; SLD = Stuttering Like-Disfluencies; SPM = Syllables Per Minute; WPM = Words Per Minute; SSI-3 = Stuttering Severity Instrument; $\mathbf{S D}=$ Standard Deviation.

Table 2. Descriptive statistics for stuttering-like disfluencies of duration and repetition in the two different listening conditions: non-altered and delayed auditory feedback

\begin{tabular}{cccccccc}
\hline Types of SLD & AF & X & N & Min & Max & SD & P \\
\hline \multirow{2}{*}{ SLD of Duration } & NAF & 7.97 & 30 & 1.00 & 40.00 & 7.86 & \multirow{2}{*}{0.828} \\
& DAF & 7.63 & 29 & 0.00 & 26.00 & 6.17 & \\
\multirow{2}{*}{ SLD of Repetition } & NAF & 9.63 & 30 & 1.00 & 33.00 & 8.31 & \multirow{2}{*}{$0.028^{\mathrm{a}}$} \\
\hline
\end{tabular}

Wilcoxon Signed Posts test

Legend: $\mathbf{S L D}=$ Stuttering Like-Disfluencies; $\mathbf{A F}=$ Auditory Feedback; NAF $=$ Non-altered Auditory Feedback; $\mathbf{D A F}=$ Delayed Auditory Feedback; $\mathbf{X}=$ Mean; $\mathbf{N}=$ Number of individuals who presented the variable; Min = Minimum; Max = Maximum; $\mathbf{S D}=$ Standard Deviation; $\mathbf{P}=\mathbf{P}$ value.

aSignificant difference. 
Table 3. Descriptive statistics for each type of stuttering-like disfluencies under two different listening conditions: non-altered and delayed auditory feedback

\begin{tabular}{|c|c|c|c|c|c|c|c|}
\hline SLD & AF & $\mathbf{X}$ & $\mathbf{N}$ & Min & Max & SD & $\mathbf{P}$ \\
\hline \multirow{2}{*}{ Block } & NAF & 4.23 & 26 & 0.00 & 28.00 & 5.98 & \multirow{2}{*}{0.556} \\
\hline & DAF & 3.63 & 21 & 0.00 & 19.00 & 4.67 & \\
\hline \multirow{2}{*}{ Prolongation } & NAF & 3.17 & 27 & 0.00 & 13.00 & 3.22 & \multirow{2}{*}{0.928} \\
\hline & DAF & 3.13 & 24 & 0.00 & 11.00 & 3.14 & \\
\hline \multirow{2}{*}{ Word Repetition } & NAF & 4.93 & 27 & 0.00 & 19.00 & 4.89 & \multirow{2}{*}{$<0.001^{a}$} \\
\hline & DAF & 3.17 & 21 & 0.00 & 17.00 & 4.32 & \\
\hline \multirow{2}{*}{ Part of Word Repetition } & NAF & 3.07 & 24 & 0.00 & 16.00 & 4.08 & \multirow{2}{*}{0.203} \\
\hline & DAF & 3.57 & 24 & 0.00 & 17.00 & 4.36 & \\
\hline \multirow{2}{*}{ Sound Repetition } & NAF & 1.63 & 21 & 0.00 & 8.00 & 1.83 & \multirow{2}{*}{0.089} \\
\hline & DAF & 1.27 & 19 & 0.00 & 5.00 & 1.31 & \\
\hline \multirow{2}{*}{ Pause } & NAF & 0.57 & 9 & 0.00 & 4.00 & 1.01 & \multirow{2}{*}{0.293} \\
\hline & DAF & 0.83 & 14 & 0.00 & 4.00 & 1.12 & \\
\hline \multirow{2}{*}{ Intrusion } & NAF & 0.20 & 5 & 0.00 & 2.00 & 0.48 & \multirow{2}{*}{0.480} \\
\hline & DAF & 0.27 & 2 & 0.00 & 6.00 & 1.14 & \\
\hline
\end{tabular}

Wilcoxon Signed Posts test

Legend: $\mathbf{S L D}=$ Stuttering Like-Disfluencies; $\mathbf{A F}=$ Auditory Feedback; NAF = Non-altered Auditory Feedback; DAF = Delayed Auditory Feedback; $\mathbf{X}=\mathbf{M e a n} ; \mathbf{N}=$ Number of individuals who presented the variable; Min = Minimum; Max = Maximum; $\mathbf{S D}=$ Standard Deviation; $\mathbf{P}=\mathrm{P}$ value.

a Significant difference.

Table 4. Distribution of the number and percentage of individuals who presented decrease, increase or maintained the number of each type of stuttering-like disfluencies under the effect of delayed auditory feedback

\begin{tabular}{ccccc}
\hline \multirow{2}{*}{ SLD } & \multicolumn{3}{c}{ Listening condition with DAF } & \multirow{2}{*}{ P } \\
\cline { 2 - 4 } & Decreased & Increased & Maintained & \\
\hline Block & $14(47 \%)$ & $10(33 \%)$ & $6(20 \%)$ & 0.225 \\
Prolongation & $15(50 \%)$ & $11(37 \%)$ & $4(13 \%)$ & 0.133 \\
Word Repetition & $19(63 \%)$ & $1(3 \%)$ & $10(34 \%)$ & $0.009 \mathrm{a}$ \\
Parto of Word Repetition & $9(30 \%)$ & $14(47 \%)$ & $7(23 \%)$ & 0.239 \\
Sound Repetition & $12(40 \%)$ & $5(17 \%)$ & $13(43 \%)$ & 0.242 \\
Pause & $5(17 \%)$ & $9(30 \%)$ & $16(53 \%)$ & 0.085 \\
Intrusion & $4(13 \%)$ & $1(3 \%)$ & $25(84 \%)$ & $<0.001^{\text {a }}$ \\
\hline
\end{tabular}

Chi-square Test for proportions.

Legend: $\mathbf{S L D}=$ Stuttering Like-Disfluencies; $\mathbf{D A F}=$ Delayed Auditory Feedback; $\mathbf{P}=\mathbf{P}$ value.

a Significant difference.

Table 5. Descriptive statistics for the percentage of stuttering-like disfluency and speech rate in the two listening conditions: non-altered and delayed auditory feedback

\begin{tabular}{cccccccc}
\hline Variables & AF & $\mathbf{X}$ & Med & Min & Max & SD & P \\
\hline \multirow{2}{*}{ \% Stuttering-Like Disfluencies } & NAF & 8.90 & 6.25 & 3.00 & 36.50 & 6.96 & \multirow{2}{*}{0.158} \\
& DAF & 7.93 & 5.75 & 1.00 & 28.00 & 6.43 & \\
Syllables Per Minute & NAF & 151.33 & 162.15 & 30.00 & 292.00 & 67.79 & \multirow{2}{*}{$0.046^{\mathrm{a}}$} \\
\multirow{2}{*}{ Words Per Minute } & DAF & 140.04 & 124.52 & 33.00 & 245.00 & 62.51 & \\
& NAF & 85.80 & 87.35 & 20.00 & 157.00 & 37.73 & \multirow{2}{*}{0.095} \\
\hline
\end{tabular}

Wilcoxon Signed Posts test

Legend: AF = Auditory Feedback; NAF = Non-altered Auditory Feedback; DAF $=$ Delayed Auditory Feedback; $\mathbf{X}=$ Mean; Med = Median; Min = Minimum; Max = Maximum; $\mathbf{S D}=$ Standard Deviation; $\mathbf{P}=\mathrm{P}$ value.

a Significant difference. 
The individuals were separated into two groups, the 19 that presented reduction of the word repetitions (G1) and the 11 that did not present reduction of word repetitions (G2) with the DAF. The intergroup comparison performed by the Mann-Whitney test showed that the groups were similar in age $(G 1=17.05, G 2=19.27$, $p=0.073$ ), percentage of stuttering-like disfluencies ( $G 1=9.18, G 2=8.41, p=0.860)$ and total score of the stuttering severity instrument $(\mathrm{G} 1=23.89, \mathrm{G} 2=22.80$, $p=0.980)$. The Anova test was applied to compare the flow of syllables per minute $(\mathrm{G} 1=147.73, \mathrm{G} 2=$ 157.56, $p<0.010$ ) and showed that the individuals who reduced the word repetition presented in the non-altered listening condition lower speech rate in relation to the individuals who did not decrease this typology.

\section{DISCUSSION}

The delayed auditory feedback in the persons who stutter caused as immediate effect a significant reduction in the frequency of word repetitions. Two plausible explanations for this finding may be listed: (1) Word repetition is repetition disfluency considered to be stuttering-like disfluency whose linguistic unity is greater, that is, the word is larger than a part of the word (or syllable) and that a sound (phoneme or element of a diphthong) would therefore intensify the chorus effect, making monitoring of auditory feedback more effective; (2) To be considered as stuttering-like disfluency, word repetition occurred above 3 repetitions, in this sense the result suggests that the higher the number of repetitions, the greater the effect of DAF.

The effect of delayed auditory feedback on disfluencies of duration (block, prolongation and pause) and repetition (word, part of word and sound repetition) showed a statistically significant decrease only in repetition disfluencies. This result can be justified due to a significant reduction in the frequency of word repetitions.

Considering that many variables can influence the effects caused by delayed auditory feedback in persons who stutter, such as age, severity, stuttering subtype, among others, this finding regarding the word repetition is very relevant, since the group maintained a pattern of reduction of specific stuttering-like disfluencies - word repetitions (up to 3 times) - even with all participants' heterogeneity.

Regarding the stuttering severity, the analysis showed that all individuals with very severe stuttering reduced the frequency of word repetitions, $71.4 \%$ of individuals with mild stuttering and $54 \%$ of individuals with moderate stuttering also showed a decrease of this typology. The group of individuals who reduced the word repetitions was composed of $52.6 \%$ of mild stuttering, $31.6 \%$ of moderate stuttering and $15.8 \%$ of very severe stuttering. Previous investigations have reported that the effect of DAF is better in cases of more severe stuttering in relation to mild stuttering ${ }^{18,27-29}$.

The data suggest that the reduction the number of word repetitions may be one of the first effects of DAF, since this was the first contact of individuals with this resource. It is believed that, with the greatest time of exposure to delayed auditory feedback, there is an improvement in other typologies, based on familiarity and learning of the use of the resource. However, these findings disagree with previous results that found an immediate reduction with more frequency of blocks in relation to repetitions ${ }^{18}$. Interestingly, the number of individuals was the same in this research and the study by Unger and collaborators ${ }^{18}$. However, some differences in the design of the study may justify the divergences of the findings. Unger and collaborators ${ }^{18}$ were adults (mean $=36.5$ years), and in addition to the delay effect, the alteration in the feedback frequency was used concomitantly.

In addition to the motor control strategies used by participants during speech under the delayed listening condition being variables from individual to individual, other point to be discussed refers to the number of units repeated during the occurrence of disfluencies. It is assumed that the number of repeated units may also influence the delay effect, and may explain the diverse result found among the various types of repetition disfluencies. This hypothesis is based on the fact that the number of repeated linguistic units of part of word and sound repetitions could be one or more. However, the word repetition to be considered stuttering-like disfluency should have at least three repetitions. In this way, studies that specifically analyze disfluency repetitions and their characteristics under the delayed listening condition are necessary to clarify these findings better.

The literature in the area of the auditory resources used in the therapeutic intervention of stuttering reports that the responses are diverse ${ }^{16,18-21,28,30}$. The results of this study corroborate this literature, because there was no tendency of individuals to decrease, increase or maintain the different types of stuttering-like disfluencies, except for the word repetitions, which most part of individuals reduced, and for the intrusion, since 
there was a tendency for individuals to maintain this disfluency.

In addition, the effect of DAF was variable in the occurrence of various disfluencies, such as blocks and prolongations. These findings differ from a previous study in which the reduction of the blocks showed significantly greater than the prolongations and the repetitions ${ }^{18}$. It is known that stuttering is associated with deficiencies in the cortical auditory system during speech movement planning, and this specific deficiency may contribute to inefficient monitoring of auditory feedback ${ }^{11}$. Individual differences between individuals with stuttering in relation to this sensorimotor integration may justify the variability of these results. One of the possible differences could be related to auditory abilities. A recent study showed that DAF promoted fluency only in the stuttering group without alteration in central auditory processing ${ }^{31}$. In addition, another variable that needs to be investigated is the duration of the blocks. Possibly, the delay effect is greater on blocks of longer duration.

It is possible to elucidate that, in relation to the occurrence of pauses and intrusions, it was little prevalent in the evaluation with the NAF, reinforcing the findings of previous studies ${ }^{32-34}$. It should be emphasized that in the listening condition with NAF nine individuals presented pauses, whereas in the listening condition with DAF 14 individuals manifested this typology. One possible justification for this finding is that the pause may have been used as a resource to reduce the speech rate in the attempt that the uttered speech could be simultaneous to the delayed auditory feedback that the individual was receiving. This data is coherent with the reduction of flow of SPM caused by delayed auditory feedback in this study.

The flow of syllables per minute presented a statistically significant reduction. Therefore, the delay in auditory feedback caused a reduction in articulatory rate. The flow of WPM represents the flow of information, and this measure is important for the analysis of the effect of speech therapy, since one of the general objectives of the intervention in stuttering is to increase the flow of information, which may be reduced due to the presence of excessive disfluencies. This information is very relevant since, although the reduction of the articulatory rate, there was no impairment in the flow of information.

Previous studies have described the effect of delayed auditory feedback under the speech rate of persons who stutter ${ }^{18,19,21,27,28}$. The most recent, unlike this study, revealed that DAF reduced the number of stuttering-like disfluencies without, however, decreasing the speech rate ${ }^{21,31}$, thus weakening the hypothesis that the positive effect caused on stuttering through this resource would be related to a reduced speech rate re-37. $^{35}$. In view of the diversity of the findings, it can be stated that the improvement in fluency is not only subordinate to the reduction of the speech rate ${ }^{18,38-40}$, and that the heterogeneity of the methods performed for the development of studies with delayed auditory feedback does not allow a response or response tendency capable of being considered consistent on the efficacy of this resource ${ }^{28,29}$. However, the findings of this study suggest that the reduction of articulation rate accompanied the decrease of word repetitions.

\section{CONCLUSION}

The immediate effect of delayed auditory feedback was positive in persons who stutter, because it caused a reduction in the frequency of words repetitions. There was also a decrease in the flow of syllables per minute or articulatory rate.

\section{ACKNOWLEDGEMENTS}

To Coordenação de Aperfeiçoamento de Pessoal de Nível Superior - CAPES for the support granted in the form of a masters scholarship to carry out this research.

\section{REFERENCES}

1. Hudock D, Kalinowski J. Stuttering inhibition via altered auditory feedback during scripted telephone conversations. Int $\mathrm{J}$ Lang Commun Disord. 2014;49(1):139-47.

2. Bleek B, Reuter M, Yaruss JS, Cook S, Faber $\mathrm{J}$, Montag C. Relationship between personality characteristics of people who stutter and the impact of stuttering on everyday life. J Fluency Disord. 2012;37(4):325-33.

3. Civier O, Bullock D, Max L, Guenther FH. Computational modeling of stuttering caused by impairments in a basal ganglia thalamo-cortical circuit involved in syllable selection and initiation. Brain Lang. 2013;126(3):263-78.

4. Cook S, Donlan C, Howell P. Stuttering severity, psychosocial impact and lexical diversity as predictors of outcome for treatment of stuttering. $J$ Fluency Disord. 2013;38(2):124-33. 
5. Sasisekaran J. Nonword repetition and nonword reading abilities in adults who do and do not stutter. J Fluency Disord. 2013;38(3):275-89.

6. Liu J, Wang Z, Huo Y, Davidson SM, Klahr K, Herder $\mathrm{CL}$ et al. Functional imaging study of self-regulatory capacities in persons who stutter. PLoS One. 2014;27(2):898-91.

7. Packman A. Theory and therapy in stuttering: a complex relationship. J Fluency Disord. 2012;37(4):225-33.

8. Oliveira BV, Domingues CEF, Juste FS, Andrade CRF, Ferreira DM. Familial persistent developmental stuttering: genetic perspectives. Rev Soc Bras Fonoaudiol. 2012;17(4):489-94.

9. Cai S, Beal DS, Ghosh SS, Tiede MK, Guenther FH, Perkell JS. Weak responses to auditory feedback perturbation during articulation in persons who stutter: evidence for abnormal motor-auditory transformation. PLoS ONE. 2012;7(7):e41830.

10. Braun AR, Varga M, Stager S, Schulz G, Selbie $S$, Maisog JM et al. Altered patterns of cerebral activity during speech and language production in developmental stuttering. An $\mathrm{H} 2(15) \mathrm{O}$ positron emission tomography study. Brain. 1997;120(Pt 5):761-84.

11. Daliri A, Max L. Modulation of auditory processing during speech movement planning is limited in adults who stutter. Brain Lang. 2015;143:59-68.

12. Howell P, Williams S. Development of auditory sensitivity in children who stutter and fluent children. Ear Hear. 2004;25(3):265-7.

13. Hargrave S, Kalinowski J, Stuart A, Armson J, Jones, K. Effect of frequency-altered feedback on stuttering frequency at normal and fast speech rates. J Speech Hear Res. 1994;37(6):1313-9.

14. Hudock D, Dayalu VN, Saltuklaroglu T, Stuart A, Zhang J, Kalinowski J. Stuttering inhibition via visual feedback at normal and fast speech rates. Int J Lang Commun Disord. 2011;46(2):169-78.

15. Ling D. Speech and the hearing-impaired child: theory and practice. 2nd ed. Washington DC: Alexander Graham Bell Association for the Deaf and Hard of Hearing; 2002.

16. Antipova EA, Purdy SC, Blakeley M, Williams S. Effects of altered auditory feedback (AAF) on stuttering frequency during monologue speech production. J Fluency Disord. 2008;33(4):274-90.

17. Ratyńska J, Szkiełkowska A, Markowska $R$, Kurkowski $M$, Mularzuk $M$, Skarżyński $H$. Immediate speech fluency improvement after application of the Digital Speech Aid in stuttering patients. Med Sci Monit. 2012;18(1):9-12.

18. Unger JP, Gluck CW, Cholewa J. Immediate effects of AAF devices on the characteristics of stuttering: a clinical analysis. J Fluency Disord. 2012;37(2):22-34.

19. Ritto AP, Juste FS, Andrade CRF. The effect of the SpeechEasy ${ }^{\circledR}$ device on acoustic and speech motor parameters of adults who stutter. Audiol Commun Res. 2015;20(1):1-9.

20. Chesters J, Baghai-Ravary L, Möttönen R. The effects of delayed auditory and visual feedback on speech production. $J$ Acoust Soc Am. 2012;137(2):873-83.

21. Carrasco ER, Schiefer AM, Azevedo MF. Effect of the delayed auditory feedback in stuttering . Audiol Commun Res. 2015;20(2):116-22.

22. Lloyd LL, Kaplan H. Audiometric interpretation: a manual $\mathrm{O}$ basic audiometry. Ed. Baltimore: University Park Press; 1978.

23. Gregg BA, Yairi E. Disfluency patterns and phonological skills near stuttering onset. J Commun Disord. 2012;45(6):426-38.

24. Riley GD. Stuttering severity instrument for young children (SSI-3) 3r ed. Austin, TX: Pro-Ed; 1994.

25. Andrade CRF. Fluência. In: Andrade CRF, Béfi-Lopes DM, Fernandes FDM, Wertzner HF (Orgs). ABFW - Teste de linguagem infantil nas áreas de fonologia, vocabulário, fluência $\mathrm{e}$ pragmática. Carapicuíba, SP: Pró-Fono; 2011. p. 61-74.

26. Pinto JCBR, Schiefer AM, Ávila CRB. Disfluencies and speech rate in spontaneous production and in oral reading in people who stutter and who do not stutter. Audiol Commun Res. 2013;18(2):63-70.

27. Fiorin M. Comparação do efeito imediato da retroalimentação auditiva atrasada, mascarada e amplificada na fala de gagos e de não gagos [dissertação]. Marília (SP): Faculdade de Filosofia e Ciências da Universidade Estadual Paulista "Julio de Mesquita Filho", UNESP; 2014.

28. Borsel JV, Sierens S, Pereira MMB. Realimentação auditiva atrasada e tratamento de gagueira: evidências a serem consideradas. Pró-Fono $\mathrm{R}$ Atual Cient. 2007;19(3):323-32.

29. Andrade CRF, Juste FS. Systematic review of delayed auditory feedback effectiveness for stuttering reduction. $J$ Soc Bras Fonoaudiol. 2011;23(2):187-91. 
30. Armson J, Kiefte M, Mason J, De Croos D. The effect of SpeechEasy on stuttering frequency in laboratory conditions. J Fluency Disord. 2006;31(2):137-52.

31. Picoloto LA, Cardoso ACV, Cerqueira AV, Oliveira CMC. Effect of delayed auditory feedback on stuttering with and without central auditory processing disorders. CoDAS. 2017;29(6):1-7.

32. Juste FS, Andrade CRF. Tipologia das rupturas de fala e classes gramaticais em crianças gagas e fluentes. Pró-Fono R Atual Cient. 2006;18(2):129-40.

33. Oliveira CMC, Yasunaga CN, Sebastião LT, Nascimento EN. Familiar counseling and its effects on childhood stuttering. Rev Soc Bras Fonoaudiol. 2010;15(1):115-24.

34. Oliveira CMC, Fiorin M, Nogueira PR, Laroza CP. Speech Fluency Profile: comparative analysis between the sporadic and familial persistent developmental stuttering. Rev. CEFAC. 2013;15(1):1627-34.

35. Curlee RF. Stuttering and related disorders of fluency. New York: Thieme, 1993.

36. Perkins WH. Stuttering disorders. New York: Thieme-Stratton, 1984.

37. Ryan BP. Programmed therapy for stuttering in children and adults. 2nd ed. Springfield: CC Thomas, 2010.

38. Armson J, Kiefte M. The effect of SpeechEasy on stuttering frequency, speech rate, and speech naturalness. J Fluency Disord. 2008;33(2):120-34.

39. Sparks G, Grant DE, Millay K, Walker-Batson $D$, Hynan LS. The effect of speech rate on stuttering frequency during delayed auditory feedback. J Fluency Disord. 2002;27(3):187-201.

40. Stuart A, Kalinowski J, Rastatter MP. Effect of monaural and binaural altered auditory feedback on stuttering frequency. J Acoust Soc Am. 1997;101 (6):3806-9. 